Thorax (1972), 27, 503.

\title{
Epicardial cyst - a case report
}

\author{
M. H. EDWARDS and A. AHMAD
}

The Brompton Hospital, London

The first successful removal of an epicardial cyst is reported. Evidence is presented to demonstrate that the cyst developed as a result of an abnormality occurring within the first five weeks of fetal life.

Pericardial cysts are well recognized, comprising $7 \%$ of all mediastinal tumours (Nelson, Shefts, and Bowers, 1957). Unilocular, thin-walled sacs, they lie usually in the anterior costophrenic angle in close association with the pericardium. They contain clear fluid and occasionally communicate with the pericardial cavity.

In contrast, a similar cyst arising inside the pericardial cavity, and attached to the heart, is exceedingly rare. Only three reports showing any resemblance to the case described below have been found in the literature. Gould (1960) described an intrapericardial cyst in a stillborn child, as well as a small multilocular cyst arising from the ventricle of an adult also found at necropsy. Piwnica and Ménage (1962) described the successful removal of a large cyst arising from between the aorta and the pulmonary artery in a child. Preoperative irradiation had destroyed the cyst lining, but the site of the cyst suggests that it was bronchogenic rather than pericardial in origin.

Although the cyst described below may be unique, it has relevance to the aetiology of pericardial cysts in general.

\section{CASE REPORT}

R.D., a 43-year-old electrical engineer, was admitted to hospital in February 1969 for investigation. For the previous two years he had noticed slight breathlessness on climbing stairs and an enlarged cardiac silhouette had been reported on mass miniature radiography. He had been treated for rheumatic fever at the age of 7 years. He smoked 20 cigarettes a day until 1964 and consumed moderate quantities of alcohol.

Examination revealed a healthy, heavily built man; there were no abnormal physical signs except an increased jugular ' $a$ ' wave and reversed splitting of the second heart sound in the pulmonary area. The pulse rate was regular at 80 beats per minute and the blood pressure was $110 / 70 \mathrm{mmHg}$.
Routine investigations showed no haematological or biochemical abnormality, and in particular the white cell count, blood urea, protein-bound iodine and serum cholesterol levels were within normal limits.

Chest radiographs confirmed the presence of moderate cardiac enlargement without abnormality of the pulmonary vasculature (Figs. 1 and 2).

Right and left heart catheterization demonstrated normal haemodynamics apart from raised end-diastolic pressures in the right ventricle $(6-9 \mathrm{mmHg})$ and in the left ventricle $(10-15 \mathrm{mmHg})$.

Cineangiography was performed by injection of contrast medium into the right atrium, showing that all the heart chambers were displaced to the right by a large mass situated on the left lateral aspect of the heart (Fig. 3). The mass was very unyielding to left ventricular movement.

OPERATION A left anterolateral thoracotomy was performed through the fifth intercostal space. The pericardium was healthy and was opened in front of the phrenic nerve. The pericardial cavity contained a little clear fluid and a large, tense, unilocular, thinwalled cyst displacing the heart to the right.

After removing approximately $500 \mathrm{ml}$ of clear straw-coloured fluid from the cyst, its attachment to the heart near the coronary sinus, well clear of the pulmonary veins and the oblique vein of Marshall, was visible; the cyst wall was excised completely, except for a small area at its base which was fused with the visceral pericardium. The parietal pericardium was left partly open and the thoracotomy wound was closed after draining the left pleural cavity.

The patient made a satisfactory recovery apart from the development of a pericardial effusion. One month after operation the pericardial cavity was drained of 2 litres of old blood through a subcostal incision. Subsequently the patient continued to improve and is now fit and well.

A radiograph taken three months after thoracotomy showed diminution of the size of the heart shadow (Fig. 4).

Histological examination of the cyst demonstrated a fibrous wall lined by a layer of flattened cells. 


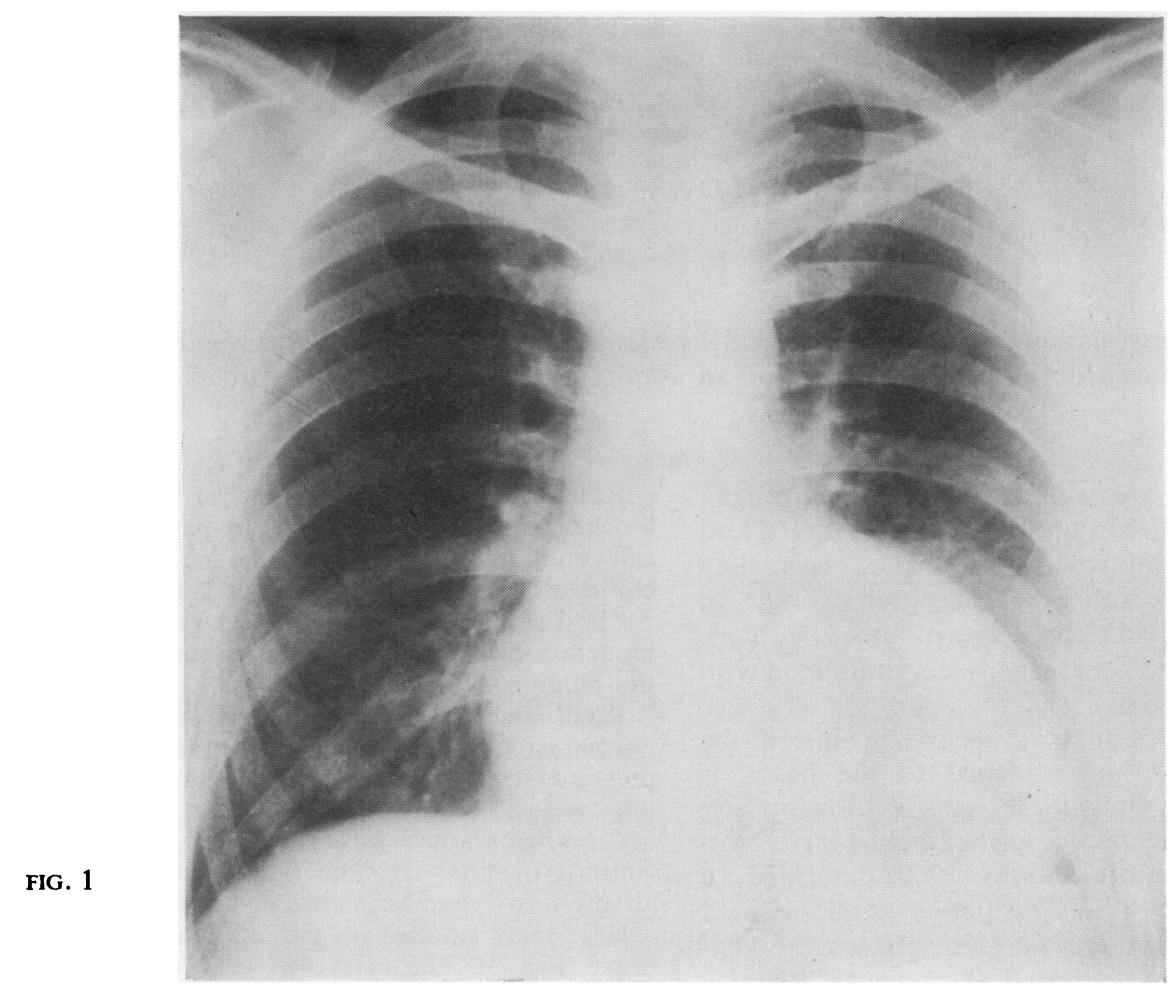

FIGS. 1 and 2. Moderate enlargement of the cardiac outline.

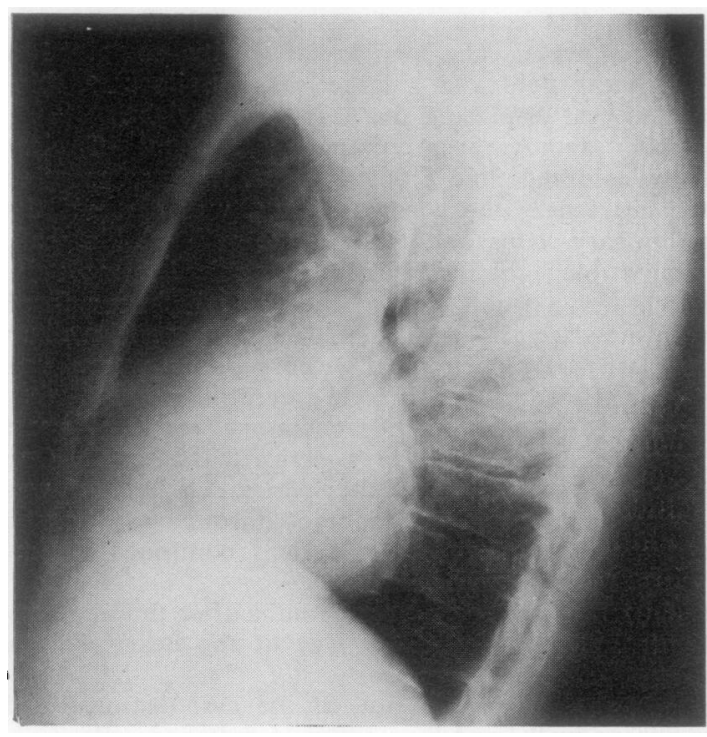

FIG. 2

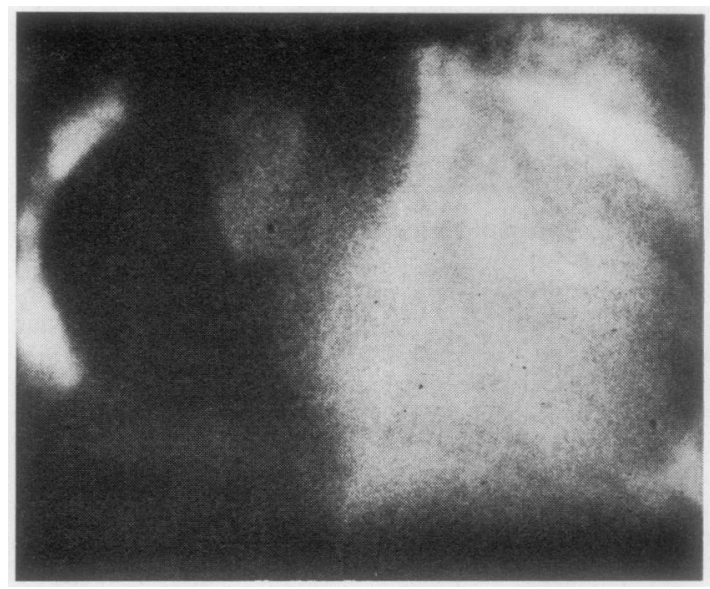

FIG. 3. Cineangiography shows that all the chambers are displaced to the right by a mass situated on the left lateral aspect of the heart. 


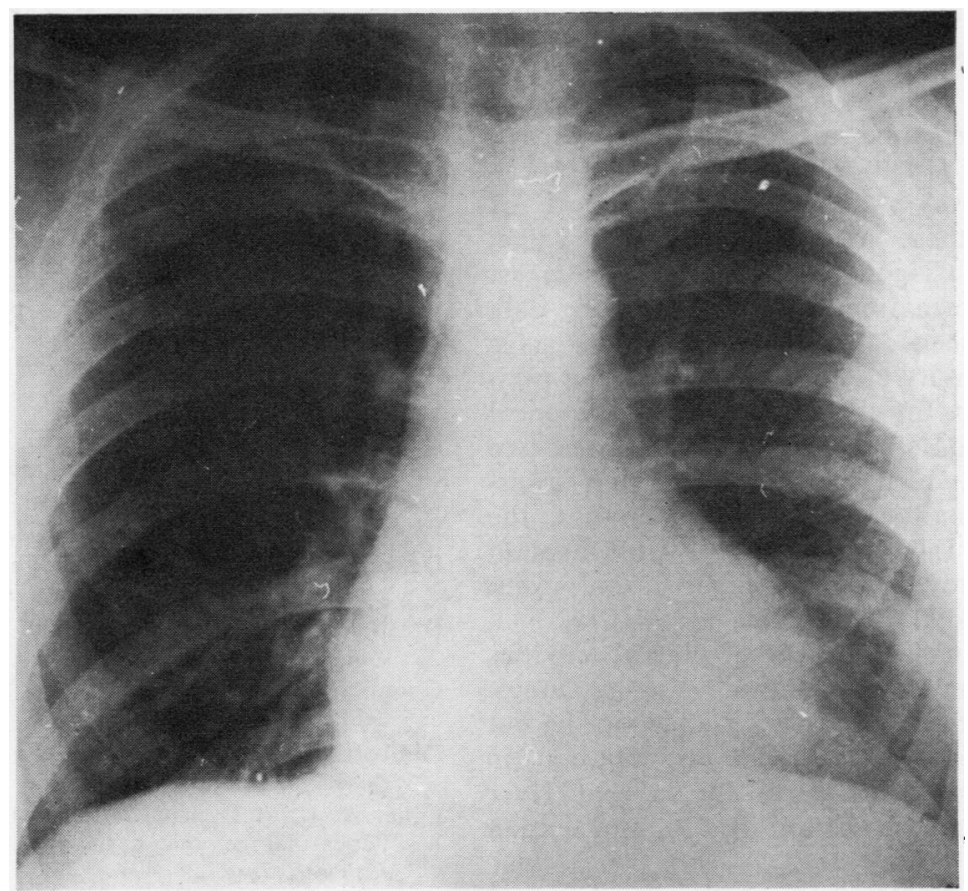

FIG. 4. Radiography three months after excision of the cyst shows a diminution of the size of the heart shadow.

\section{DISCUSSION}

Cystic lesions arising in the mediastinum have been extensively reviewed (Davis, Dorsey, and Scanlon, 1953; De Roover, Maisin, and Lacquet, 1963). Those found inside the pericardium, on the other hand, are less well known but have been described by Loehr (1952) in an excellent survey of cyst-like shadows inseparable radiologically from the heart and pericardium. Chronic pericarditis or tuberculosis may be preceded by bouts of illness; tuberculous foci are seen in the lungs and calcification in the pericardium is usually visualized on radiographs. The pericardium is chronically inflamed and tubercle bacilli may be isolated. Loehr stresses that hydatid disease of the pericardium is nearly always secondary to rupture of a cyst in the myocardium, and that the calcified walls of these myocardial cysts can be seen radiographically. Perlstein (1918) reported that malignant tumours of the heart and pericardium, whether primary or secondary, usually progress rapidly and show evidence of metastasis clinically and radiogically at an early stage, but added that pericardial effusions and cystic degenerations were common.
Benign cysts inside the pericardial cavity show the same structures as those outside. On rare occasions a teratomatous cyst can be diagnosed radiographically by the presence of teeth. At operation, hair in the cyst is diagnostic. Usually a teratoma is indistinguishable from a bronchogenic cyst until the presence of tissue from all three germ layers is seen on microscopic examination of the former. The wall of both types is usually calcified, and the fluid contents are viscid, varying in colour from yellow to muddy brown. However, Dabbs, Berg, and Peirce (1957) suggested that branchogenic cysts were usually attached to the region of the great vessels, whereas teratomas were more likely to be found at the side of the heart itself.

There has been no convincing report of intrapericardial lymphangiomatous cysts, but, when found outside the pericardial cavity, they are usually multiple, of various sizes, fused with mediastinal tissue, and contain crystal-clear fluid. The lining of the cyst wall consists of a layer of flattened endothelial cells, identical with that of a pericardial cyst, so that the distinction between the two depends on the macroscopic appearances.

It was, therefore, concluded that the cyst described above was derived from pericardial 
tissue and should be called an epicardial cyst. EMBRYOLOGY Within five weeks of fertilization, small spaces in the mesoderm have coalesced around the heart tube to form the pericardial cavity. Lambert (1940) considers that extrapericardial cysts develop as a result of failure of coalescence of these mesodermal spaces. Lillie, McDonald, and Clagett (1950), however, suggest that these malformations occur at a later date when the coalescence is complete; at this stage the pericardial cavity communicates with the peritoneum by means of the paired pleuroperitoneal canals running dorsally, and also possesses two ventral recesses which end in the septum transversum. Abnormalities of development of the ventral recesses, Lillie et al. claim, would explain not only the presence of extrapericardial cysts, but also pericardial diverticula.

However, even later, as the pleural cavities enlarge to accommodate the developing lungs, folds appear in the pleural lining and may be cut off to produce extrapericardial cysts. Kindred, in a personal communication to Drash and Hyer (1950), demonstrated a section of a $30 \mathrm{~mm}$ human fetus with this infolding clearly shown.

A satisfactory explanation of the development of a pericardial cyst from the visceral pericardium is afforded by Lambert's theory of failed coalescence of pericardial lacunae.

It is improbable that pleural infolding or abnormal development of a ventral pericardial recess would produce such a cyst, since the visceral pericardium is fully developed before these events occur. It would seem that Lambert's theory is acceptable for the aetiology of pericardial cysts both inside and outside the pericardial cavity.

We express our thanks to Mr. S. C. Lennox, Dr. J. N. Mickerson, and Dr. R. Gibson for permission to publish details of their case ; to Dr. K. F. Hinson for the histology ; to Mr. P. A. Cullum, King's College Hospital, for advice and encouragement ; and to $\mathrm{Mr}$. K. G. Morman, Chester Beatty Research Institute, for the photographs.

\section{REFERENCES}

Dabbs, C. H., Berg, R., and Peirce, E. C. (1957). Intrapericardial bronchogenic cysts. J. thorac. Surg., 34, 718.

Davis, C., Dorsey, J., and Scanlon, E. (1953). Cysts about the pericardium. Arch. Surg., 67, 110.

De Roover, Ph., Maisin, J., and Lacquet, A. (1963). Congenital pleuro-pericardial cysts. Thorax, 18, 146.

Drash, E. C., and Hyer, H. J. (1950). Mesothelial mediastinal cysts. J. thorac. Surg., 19, 755.

Gould, S. E. (1960). Pathology of the Heart. Thomas, Springfield, Illinois.

Lambert, A. V. S. (1940). Etiology of thin-walled thoracic cysts. J. thorac. Surg., 10, 1.

Lillie, W. I., McDonald, J. R., and Clagett, O. T. (1950). Pericardial celomic cysts and pericardial diverticula. J. thorac. Surg., 20, 494.

Loehr, W. M. (1952). Pericardial cysts. Amer. J. Roentgenol., 68, 584.

Nelson, T. G., Shefts, L. M., and Bowers, W. F. (1957). Mediastinal tumours; an analysis of 141 cases. Dis. Chest, 32, 123.

Perlstein, I. (1918). Sarcoma of the heart. Amer. J. med. Sci., 156, 214.

Piwnica, A., and Ménage, C. (1962). Les tumeurs kystiques intra-péricardiques. J. Chir. (Paris), 84, 543. 